\title{
A qualitative study exploring barriers to adequate uptake of antenatal care in pre-conflict Syria: Implications for post conflict interventions addressing the demand-side barriers
}

Rima Mourtada ( $\nabla$ rima.mourtada@yahoo.co.uk)

Population Council https://orcid.org/0000-0002-4009-3411

Hyam Bashour

Damascus University

Fiona Houben

Canterbury Christ Church University

Research

Keywords: Antenatal care, Conflict, Syria

Posted Date: July 20th, 2020

DOI: https://doi.org/10.21203/rs.3.rs-41742/v1

License: (우 This work is licensed under a Creative Commons Attribution 4.0 International License. Read Full License 


\section{Abstract \\ Background}

Until the onset of the conflict in 2011, Syria has made noticeable progress in reducing maternal mortality and morbidity. Despite the improvement in antenatal care (ANC) coverage and patterns of use, analyses of national surveys demonstrated wide regional variations in uptake, timing and number of visits even after controlling for women's socio-demographic characteristics. The main aim of this study is to highlight the barriers to women's adequate uptake of ANC that existed in Syria pre-conflict, comparing two governorates: Latakia, where uptake of antenatal care was high and Aleppo, where uptake of ANC was low.

\section{Methods}

This qualitative study carried out 30 in-depth interviews with (18-45 year old) pregnant women from Aleppo and Latakia and conducted 15 participant observation sessions in different types of health facilities that provide ANC. Participants were purposively recruited from randomly selected rural and urban, public and private health facilities, and independent midwives' clinics, with onward sampling of women who did not attend ANC. Transcripts and fieldnotes were analyzed using the framework approach.

\section{Results}

Inadequate uptake of ANC in Aleppo included not attending ANC, discontinuing care or seeking care with unqualified providers. Three themes emerged that explained the disparities in uptake of ANC in Aleppo compared to Latakia: women's assessment of their own health status in pregnancy, women's evaluation of the risks of seeking ANC, and women's appraisal of the value of different types of service providers. These evaluations were connected with the availability, accessibility (geographical and financial) and acceptability of ANC services however women's views were shaped by the knowledge and prevailing opinions in their families and community.

\section{Conclusions}

Findings are utilized to discuss low-cost interventions addressing the disparities in uptake of ANC. Interventions should be aimed at increasing vulnerable women's capacity and capabilities to make informed decisions. Women's groups that foster education and empowerment and which have been effective in other low resource settings are worth exploring in Syria. Increased use of mobile phones and social media platforms that were not present pre-conflict, suggests mobile health technologies (mHealth) may present efficient platforms to deliver these interventions.

\section{Background}


A substantial number of women of reproductive-age still suffer from pregnancy-related complications that cause maternal and neonatal morbidity and mortality, most of which take place in low and middle-income countries (LMICs) $(1,2)$. Most interventions, often introduced during antenatal care (ANC), improve the health of the mothers and the neonates concurrently (3).

ANC is defined as the care provided by skilled health-care providers to pregnant women and adolescent girls in order to ensure the best health conditions for both mother and baby during pregnancy (4). It is recommended that ANC should be initiated in the first trimester of pregnancy because most interventions should be implemented early in order to be effective $(5,6)$. A minimum number of visits is important. The World Health Organization (WHO) formerly recommended four focused ANC visits for low-risk pregnancies with additional visits for high risk women following the 1990 model (7), however, this model was found to be associated with higher perinatal deaths compared to the model advocating for 8 visits (8). Consequently, WHO's updated model in 2016 recommended 8 ANC visits; one visit in the first trimester, 2 visits in the second trimester and 5 visits in the third trimester (8).

Given the prominent role of ANC in protecting the health of mothers and babies, understanding the factors that influence women's access to and uptake of ANC services is extremely important in order to address any barriers that prevent demand for or provision of such services. The health services "access" concept is a function of demand and supply. Demand-side factors are defined as "those factors that affect demand and that operate at the individual, household or community level" whereas supply side factors are "factors derived from the health care production function, that interact to produce effective health care services" (9). Access is hampered when individuals do not use services that could be beneficial to them on the demand side or when good quality effective care is not offered on the supply side, and both demand and supply sides are related (10). Most studies that examine access to health care use frameworks that include three dimensions that have supply and demand elements as described by Peters et al (11):

1. Availability: having the right type of care available to those who need it, such as hours of operation and waiting times that meet demands of those who would use care, as well as having the appropriate type of service providers and materials (11).

2. Geographic accessibility:

a. Geographical accessibility: the physical distance or travel time from service delivery point to the user (11).

b. Financial accessibility: the relationship between the price of services (in part affected by their costs) and the willingness and ability of users to pay for those services, as well as be protected from the economic consequences of health costs (11).

3. Acceptability is the match between how responsive health service providers are to the social and cultural expectations of individual users and communities (11).

These three constructs are influenced by individual, household and community characteristics as well as distal determinants of health service access at the policy or macro environmental level (11). 
Individual and household factors that influence use of ANC include education, age, parity, socio-economic status, area of residence and knowledge about the characteristics of and need for medical treatment (12). Cultural, religious and other social factors are among community factors that influence use of health services and these include autonomy, religion, social support and cultural beliefs and these factors are often not captured with standard national household surveys $(9,12-14)$.

Until the onset of the conflict in 2011, Syria had made considerable progress in decreasing maternal and infant mortality. Ninety six percent of women delivered with a skilled birth attendant, and $88 \%$ had at least one ANC with a skilled attendant. However, the number of women who had at least 4 ANC visits (according to the national guidelines following WHO recommendations at the time of the study) was much lower (64\%) (14). Moreover, there were wide regional variations in ANC coverage and patterns of use (15).

Although women's socio-demographic characteristics such as age, education, socioeconomic status, area of residence and parity are important determinants of service use, secondary analyses of two earlier national surveys in Syria revealed that the regional disparities in ANC coverage and patterns of use (timing of first visit and number of visits) remained even after controlling for women's main demographics, suggesting that there are additional factors contributing to the regional disparities in ANC coverage and use patterns, which are likely related to service provision on the supply side and socio-cultural and community factors on the demand side (15).

The Syrian conflict caused destruction to many health facilities in the country (16), consequently interrupting maternal health care for many women and likely deepening divisions in care quality. Postconflict reconstruction of health services offers a unique opportunity to address the issues that existed preconflict, which contributed to the regional disparities in ANC coverage and patterns of use. Efforts to rebuild the health system in Syria are likely to focus on addressing factors on the supply side that are related to governance, infrastructure, rebuilding the destroyed health facilities and retaining the health workers (17) with the overall aim of achieving universal health coverage. However, high coverage does not always translate into positive health outcomes when health facilities are underutilized (18). Therefore, it is important to address the demand-side barriers to adequate uptake of ANC that contributed to the regional variations in ANC coverage and patterns of use that were present before the conflict.

\section{Methods}

\section{Aims of the study}

The main aim of the study is to explore barriers to women's uptake of ANC comparing two governorates in Syria, Latakia where uptake of ANC was high and Aleppo where uptake of ANC was low (as demonstrated by secondary data analyses of two earlier national health surveys). Findings are utilized to discuss potential low-cost interventions to increase women's uptake of ANC focusing on addressing the demand side barriers, which are discussed within the three dimensions of the health access model (availability, accessibility, (geographical and financial) and acceptability).

\section{Study design}


This study was carried out in 2010, shortly before the eruption of the conflict, and was part of a larger mixed-methods study that involved secondary data analysis of two national surveys (Pan Arab Project for Family Health (PAPFAM) (1996-2001) and Multiple Indicator Cluster Survey (MICS) (2004-2006), supplemented by a qualitative case study that employed in-depth interviews as well as observation sessions to explore factors affecting utilization and quality of ANC in Syria. In this paper, we present the results of the qualitative study that looked at barriers to adequate uptake of ANC presenting the perspectives of women in two governorates in Syria; Latakia where quality of care was high and Aleppo where quality of care was low (15). Inadequate uptake of ANC in this study is defined as: not seeking antenatal care, seeking care with unqualified providers or discontinuing care.

\section{Study setting}

Table 1 provides an overview of Aleppo and Latakia governorates (which they will be referred to as Aleppo and Latakia in the paper) including the population size in each governorate in 2010 at the time of the study. Aleppo is the largest and most densely inhabited Syrian governorate. Latakia is much smaller and its capital, Latakia city, is the main port city of Syria on the Mediterranean Sea.

\section{Study participants}

Participants included pregnant women aged 18-45 years living in Aleppo and Latakia attending ANC at different types of health facilities that provide ANC in Syria (private clinics/hospitals, public health centers/hospitals in urban and rural areas). We also included women who attended ANC with midwives who provided ANC independently at their own clinics in Aleppo (which was considered illegal as reported by health officials) as well as women who did not attend ANC (Table 2).

\section{Sampling and recruitment}

Purposive sampling was used to recruit the women using updated lists of gynecologists practicing privately and publicly in Aleppo and Latakia (issued in 2009 by the Syrian Society of Obstetrics and Gynaecology office, and the Ministry of Health around the same time of the study). From each list, we randomly selected one clinic/health center using the random selection number method with a calculator. We then contacted the doctor working at this health facility, explained the study and if they consented, we arranged an appointment to recruit women from their health facilities. If doctors declined to participate, we selected the clinic/health center below them on the list and contacted the doctor who worked there.

To recruit women attending ANC with midwives who provide ANC independently, we obtained the phone numbers of midwives from the health officials in Aleppo who worked at the health directorate. We contacted the midwives, explained the study and recruited women from the clinics of those who agreed to participate. There were no midwives that provided ANC independently in Latakia.

Women who did not attend ANC were recruited using the snowball technique, a type of purposive sampling, with the help of women participating in our study. We were unable to recruit women who did not attend ANC in Latakia. Our experience was confirmed by doctors and women in Latakia who claimed that almost all women in Latakia attended ANC at least once. MICS survey data in 2006 also shows that $97 \%$ of women in 
Latakia attended ANC. This percentage might have increased in 2009-2010 around the time we conducted our interviews.

We recruited 13 women attending ANC and 5 women not attending ANC in Aleppo and 12 women attending ANC in Latakia (Table 2). Twelve women in Aleppo were interviewed twice resulting in a total of 42 in-depth interviews.

\section{Data collection}

In-depth interviews and observations at ANC settings were combined to provide a comprehensive view of the situation of ANC in both governorates. In-depth interviews are ideal for collecting data on individuals' personal histories, perspectives, and experiences, especially when sensitive topics are being explored. (19). Observation sessions allowed us to better understand the different ANC settings and interactions.

Semi-structured in-depth interviews were recorded in Arabic by the first author (the researcher) as part of her PhD research. The interview guide covered the following topics: women's practices regarding their current pregnancies (and the reasons for these practices); places where they sought care, frequency of care; women's perceptions of the importance of ANC and certain elements of ANC. We interviewed some women (12 women) in Aleppo twice. Firstly, most of these women were shy or hesitant during the first interview, which might have influenced their willingness to share information about their health seeking behavior. Secondly, we wanted to explore how perceptions changed over time, given the pregnancy related physiological changes. We expected that such changes, along with the interaction with the health system may have had implications on women's health care seeking behavior. The guide was piloted with six pregnant women, three from each governorate. Women were interviewed either at their home or in a private room at health centers/clinics depending on women's preferences. The interviews lasted between around 30-45 minutes.

The researcher observed the physical settings of the clinics/health centers and the participants including women, doctors, staff and how they interacted in different settings. The observation sessions were recorded in fieldnotes. The role of the researcher was known and she engaged in the social situations that presented themselves (20-21). Fifteen observation sessions were completed, lasting for two hours on average: three sessions at private clinics ( 2 in Aleppo and 1 in Latakia), 8 sessions at health centers ( 4 in Aleppo and 4 in Latakia), 2 sessions at hospitals in Aleppo and 2 sessions at midwives' clinics in Aleppo.

\section{Data management and analysis}

Interviews were transcribed verbatim and translated into English. Data were analyzed using the framework approach, a modified version of content analysis developed for policy relevant research (22-23). The researcher familiarized herself with the data by reading the transcribed data and observational notes several times, then documented her initial impressions. Key themes were identified followed by a construction of a thematic framework that was based on issues derived from aims of study as well as persistent views or experiences that were present in the data. This process produced a detailed index, which was applied on textual data (the transcribed interviews and the field notes from the observation sessions) in a systematic manner where all data were annotated according to the thematic framework. Data were then 
rearranged according to the corresponding part of the thematic framework, which they belong to, forming thematic charts. In the final stage (mapping and interpretation), charts were reviewed carefully, examining different perceptions and experiences looking for similarities and differences and attempting to find associations between themes to provide an explanation for the findings.

\section{Results}

\section{Characteristics of study participants}

Tables 3 (Additional File 1) describes the main demographic characteristics of study participants in both governorates and the place where they attended ANC.

\section{Barriers to adequate uptake of ANC}

Three dominant themes emerged throughout the in-depth interviews that explained barriers to adequate uptake of ANC, particularly in Aleppo. These were mainly related to women's evaluation of their own health status in relation to their pregnancy, women's evaluation of risks and costs of seeking ANC, and women's evaluation of the type of services in relation to their experiences.

Theme 1: Women's assessment of their own health status in pregnancy and reasoning about the causes of ill health

Women's evaluation of their own health status and risks during pregnancy was one of the reasons why some women did not seek ANC or did not follow up with their care. Reasons for not seeking ANC were related to the lack of perceived risks of own pregnancy, such as not experiencing complications, not being primiparous, and not perceiving any benefits of ANC.

\section{Not experiencing health complications}

Women who never attended ANC or who did not seek ANC on a regular basis associated seeking care with being ill or having complications with their pregnancy. They explained that only ill women, or women having problems conceiving should follow up with their care.

Participant 4 from a village in Manbij district, Aleppo and who never visited the doctor for ANC explained: "We do not have the habit of seeking ANC here. I will go to the doctor only if I feel sick or if I bleed." She added, "Some women in the village visit the doctor but those have fertility problems."

Our observation sessions of the public health facilities in rural areas in Aleppo demonstrated that the doctor was not available on a regular basis. Additionally, the doctors practicing at such facilities were mostly males, which could have discouraged women from seeking care given the religious and traditional beliefs in those communities.

Our interviews indicated that many women believed that a woman who has a normal pregnancy and who has no symptoms of illness, does not need to seek ANC or visit the doctor. Moreover, since the habit in the 
village is for sick women or women who have fertility problems to visit the doctor, some of those women may have been worried about being perceived as unhealthy or infertile, and that this would shake their position in communities where women's main identity may be defined by her ability to conceive.

\section{Not being primaprous}

A number of multiparous women in Aleppo demonstrated less interest in following up their pregnancies. What reassured them was having at least one uncomplicated previous pregnancy. Talking about her second pregnancy, participant 6 who lived in a village in Afrin district, Aleppo explained: "I did not want to follow this pregnancy up, I tried the first pregnancy, and everything was normal."

The fear of the unknown, which these women experienced in their first pregnancy, dissipated in consequent pregnancies. Once women have experience of pregnancy and childbirth themselves, they feel there is little value in seeking care in further pregnancies. This was not the case of multiparous women in Latakia as all of them reported attending ANC regularly.

\section{Lack of perceived benefits of ANC and reasoning about the causes of ill health in pregnancy}

The main reason why some women who lived in rural Aleppo visited the health center was to get vaccinated against tetanus. The vaccination was provided at the local health center at their village free of charge. These women explained that the vaccination would protect their baby from dying. Participant 4 explained in her second interview: "I was told to get vaccinated as soon as I feel that my baby started moving, this is the habit here."

Some of the women who experienced complications found alternative explanations for their conditions and did not perceive attending ANC to be protective. For example, a number of the women in Aleppo who had miscarried believed that having had a shock, a nightmare, or the evil eye, were the reasons for the loss of their babies. One woman reported that her doctor told her that being frightened had caused her previous miscarriage. Participant 1 who lived in a village in Afrin district, Aleppo, described her miscarriage thus: "The reason for my miscarriage was being scared. I had a nightmare and I woke up, a month later, I did not feel the baby moving and then I discovered that the baby was dead and I was four months pregnant. The doctor told me it was me being scared. I had no toxoplasmosis, I did the test and everything was normal."

Participant 2 who lived in a village in Manbij district, described why she visited a sheikh (a religious man) after her first miscarriage: "People in the village told me that it is the evil eye that caused my miscarriage, so my mother and my husband advised me to go to the sheikh to disable the evil eye."

When this did not solve the problem and she had a second miscarriage, she decided to visit a private doctor. This is yet another example of women not perceiving ANC services as being helpful as some found alternative explanations for their miscarriages and the only one who sought care did so after her second miscarriage and only sought care as a last resort.

\section{Theme 2: Women's evaluation of the risks of seeking ANC services}


Women perceived there to be risks to accessing ANC. Some women in Aleppo, mostly those living in rural areas, with little formal education and low-socioeconomic status, reported the following: fear of taking the road trip to the health facility, fear of hearing false bad news, and fear of being asked to undergo a caesarean section.

\section{Concerns over the road trip}

A few women who lived in rural Aleppo and poor urban Aleppo avoided seeking ANC, as they believed that visiting the doctor while pregnant could put the woman and her baby at risk. Those women believed the car ride, especially at the beginning and end of pregnancy, could endanger the woman and her baby. For instance, the mother in law of Participant 8 who lived in Aleppo city and did not follow up with her care explained during the second interview: "I took her to a private doctor at the beginning of her pregnancy to make sure everything is fine but we did not follow up because her husband could not afford it. Also, now that she is advanced in her pregnancy, the road trip could be dangerous."

The roads in one of the areas we visited in rural Aleppo, and some of the poor areas in urban Aleppo were in a poor condition to the extent that it was difficult to reach them by car. When the roads were in good conditions, there was a lack of regular public transportation in those areas. This could explain women's reluctance to travel or to use public transport.

The road conditions in Latakia were better. Additionally, the distance that women had to travel to reach a health facility was much smaller compared to the distances that women traveled in Aleppo, even in rural areas.

\section{Fear of hearing false bad news}

Women generally try to minimize the stress they face throughout the course of their pregnancy. Some women, on the basis of stories they heard from their immediate community (family members, friends and neighbors), decided not to seek care out of concern that they would hear false bad news or be misdiagnosed. This is not only an example of women not perceiving the existing ANC services as beneficial, it is also an indication that some women perceive ANC services to be harmful. These women anticipated that hearing false bad news will add to their existing stress therefore they have decided not to seek care. This was more apparent in rural areas where women had limited access to other sources of knowledge. Participant 3 expressed her concerns and her reasons for not seeking ANC: "I worry that the doctor might tell me some bad news that will stress me out. My cousin, who was nine months pregnant, was told by her doctor that the baby's position was not right and she would need a caesarean. She was stressed out, and at the end, she had a normal delivery. This affected her and she was stressed out for a whole month."

Although some women in Latakia reported having doubts about ANC, they were not enough to prevent them from seeking care, as was the case with many women in Aleppo. Participant 27 who lived in Latakia city explained that her previous bad experience had reduced her confidence in doctors and in the effectiveness of ANC, yet she followed up her current pregnancy with a private doctor. She expressed her feelings of uncertainty and hesitation regarding regular ANC: "I monitored my previous pregnancy from the beginning and they did not discover that my baby was malformed until the end. Sometimes monitoring the pregnancy 
is useless unless both the doctor and the ultrasound are good. Sometimes you find people who do not monitor their pregnancy and everything works for them."

\section{Fear of undergoing a cesarean section}

Some women avoided seeking care due to the belief that most doctors performed unnecessary caesarean sections. For example. participant 5 who lived in a village in Manbij district, Aleppo, explained the reason why she does not attend ANC or desires to deliver with a doctor: "The midwife does not deliver you unless you are totally ready whereas the doctor gives you needles or operates on you when your delivery is delayed."

Many women in Aleppo who attended ANC with midwives reported that doctors are not as patient as midwives and perform caesarean sections immediately at delivery time. Participant 16 who lived in Aleppo city explained why she chose to attend ANC with a midwife: "Midwives have more patience, the doctor will not wait. I noticed that there were several stories where doctors did not wait, they ask for a caesarean right away."

Many women, especially those in poor Aleppo and in rural areas, reported that their knowledge of ANC practice comes from the people around them such as family, friends, and neighbors. Not only had these women avoided ANC because they did not perceive any benefits as seen with some women, these women perceived seeking care as a risky event. Therefore, they avoided ANC with certain providers such as doctors or avoided seeking ANC as whole to protect their pregnancies.

\section{Theme 3: Women's appraisal of the value of different services and their treatment by providers}

A central theme to emerge from the accounts of women who attended ANC was their preference for private care, which included care with a private doctor or a private midwife, over public health centers. This was due to the following reasons; their lack of knowledge about services offered by public health centers, their lack of trust in services offered at public health centers and bad experiences with seeking care at public health centers.

\section{Lack of knowledge about services offered by public health centers}

Some of women's ANC seeking practices suggested that various women had little knowledge about public health centers. This phenomenon was evident in both Aleppo and Latakia governorates, although more common in Aleppo. For example, participant 8 who complained in about not being informed about the availability of the tests at the health center: "The staff did not mention that / could do the tests at the health center."

Participant 21 who lived in Latakia city and attended ANC at a health center was told about the center she is currently attending by her sister. She explained: "The service here is good. I have never heard of this health 
center before. My sister told me about it. I did not even know that they have a gynecologist and an ultrasound."

\section{Lack of trust in services offered at public health centers}

Many women who were more familiar with the ANC services offered at the public health centers did not trust their quality, in particular their ability to deal with or identify complications. A few women in Aleppo expressed their preference for private care by visiting a private doctor at the beginning of their pregnancy. Once they were reassured that there were no complications, they followed up the pregnancy at a public health center. Participant 9 who lived in Aleppo city and was attending ANC at a health center, explained this point: "I visited a private doctor at the beginning of my pregnancy. She reassured me that my pregnancy was fine. Therefore, I have decided to follow up at this health center."

Other women attending public health centers in Aleppo maintained that they would seek alternative care in the private sector if complications were identified and the perceived risk outweighed the financial burden. The mother in law of participant 8, who did not follow-up with her care explained: "When she found out that she was pregnant, I brought her to the health center because her husband cannot afford the doctor. We will never visit a health center again but if anything happens like bleeding, dizziness, fatigue or back pain, we will take her to a private doctor."

\section{Poor experiences of patient-provider interactions at public health centers}

A frequently reported experience in both governorates, but more commonly reported in Aleppo, was being mistreated by doctors and staff at public health centers and public hospitals. A number of women in Aleppo criticized the treatment they received from doctors and other health staff at public health centers on many occasions. For instance, participant 9 who lived in Aleppo city explained: "You feel that they are cold, they do not make you feel comfortable, they do not understand what you want to tell them and everything is done so quickly and only the necessary things."

The researcher witnessed the impolite treatment that women experienced from doctors and staff working in health centers/hospitals in Aleppo on two occasions. On the first occasion, the doctor scolded participant 11 for failing to explain the severity of her headache saying: "How difficult could it be to tell me how severe is your headache? Why can't you do it properly?"

On the second occasion, another woman was rudely scolded by a nurse at the health center for entering the examination room by mistake. The nurse screamed at the woman saying: "How many times do we have to tell you that you should not enter this room?"

To avoid being mistreated by doctors, some women decided to seek care with midwives whom they considered as "nicer". For instance, participant 12 explained: "I have known her for a while. She delivered most of my relatives. Although it takes half an hour to get here, I prefer to seek care with her. I like her as she makes me feel good every visit. Good attitude is the most important thing. When you are sick you need someone who makes you feel at ease, especially during the last month of pregnancy." 
Similarly, participant 14 who lived in Aleppo city explained why she preferred seeking care with a midwife and not a doctor: "My parents advised me to see a doctor and told me that no matter how experienced the midwife is, the doctor will always be better but I like my midwife and I am comfortable with her so I will follow up with her. I do not like arrogant doctors. I am going there to check on my pregnancy and not to deal with arrogance. My midwife does not intimidate me and she never makes me feel I know nothing like doctors do."

Generally, the majority of women in Latakia were satisfied with how the doctors and staff treated them. This was also confirmed by the observation sessions. One example is participant 29 who lived in rural Latakia and who attended care with a private doctor at the beginning of her pregnancy but decided to follow her pregnancy up at a health center. Participant 29 explains why she followed-up the rest of her pregnancy at the health center saying: "The doctor here is so nice and has sense of humor (she smiles). She makes me feel at ease. It is all about attitude. There are some doctors who are always in a hurry, and they never listen to you. Therefore, you cannot explain anything to them. I have decided to follow-up here."

Some women in Aleppo considered seeking ANC with a private doctor because of their lack of trust in public health centers as well as being mistreated by doctors working at the public sector but were unable to do so because of their higher fees, so they either ended up discontinuing their care or they attended care with midwives who charged lower fees. Participant 8 elaborated why she does not want to follow her pregnancy up: "The private doctor is too expensive, and the treatment at the health center is really bad, so we have to depend on God now, that's all we have."

Instead of discontinuing care, some women in Aleppo chose to seek care with midwives who charged lower fees. This was brought up on several occasions as a reason that encouraged many women to seek care with midwives and not doctors. Private doctors usually charge 500 Syrian Pounds (SP) per visit and sometimes 700 SP, whereas the majority of midwives charge only 200 SP and sometimes they do not take money at all. For instance, participant 15 explained why she attended care with a midwife: "She is not expensive, I pay only 200 SP for a visit, and sometimes she does not take money, and when she refuses to take money I give her a present."

Women's current or previous experiences with different health care providers as well as experiences of family members and friends have influenced their health care seeking patterns and made them sometimes discontinue care, seek care with a particular provider, or change health providers until they felt comfortable with a particular one. Additionally, the choice of the health provider was also influenced by women's perception of the risks their own pregnancy as women were willing to seek care with an inconvenient health provider if they experienced complications.

\section{Discussion}

Overall, findings revealed three dominating themes that triggered different patterns of ANC seeking behavior, which consequently resulted in inadequate uptake of ANC, especially among vulnerable women in Aleppo (who generally had low educational level and socio-economic status and who often had limited 
mobility and reduced access to finances); not seeking ANC at all, seeking care with unqualified providers (independent midwives) or discontinuing care. Our findings indicated on several occasions that ANC services may have been more available, accessible and acceptable for women in Latakia than they were for women in Aleppo, however, they also showed that women's perceptions of ANC benefits and their accessibility and acceptability of ANC services were also shaped by traditions and the beliefs and experiences of others such as family members, friends and other women in their communities.

The majority of women who did not seek ANC were from rural Aleppo where services were often accessible (within easy reach and free of charge) but the doctors practicing at those public health centers may have not been always available. Nevertheless, even if the doctors were available, it would have been unlikely for such women to seek ANC as they were willing to seek care only when they perceived their case as risky. Women's emic definitions of risk, which affected their perception of ANC benefits, differ from the etic or medical definitions which consider any pregnant woman at risk of developing complications. Whereas in those communities, pregnancy continues to be seen as a normal event that does not require regular medical follow-up, especially among multiparous women and women who did not experience any health complications or had a normal previous delivery.

Generally, women in traditional communities worry about the harmful effect of the evil eye on the unborn baby, which obliges many women to remain discrete about their pregnancy until their baby is born (24). A number of women in rural and poor urban areas in Aleppo brought up the concept of "evil eye," and a few were convinced that it was responsible for their previous miscarriages, possibly because they were given no alternative explanations. Women's fear of the harmful effect of the "evil eye" in these communities could have discouraged them or delayed them from seeking care, as seeking ANC would have been a clear announcement of their pregnancy.

Some women stated that infertility issues or serious health problems are two essential reasons why women should seek care. Since women in traditional Arab societies gain status by their ability to produce children, seeking care might indicate that they are experiencing problems conceiving or experiencing problems with their current pregnancies, thus undermining their status in their communities. Therefore, women might feel obliged to meet the expectations of their family and community by not complaining about their health publicly in order not to compromise their position in the household and in their communities.

These perceptions of ANC were related to prevailing cultural norms and the influence of others, which resulted in not perceiving ANC as being beneficial and which could have prevented vulnerable women, who had lower educational level and socio economic status, from seeking adequate care. These findings are in line with findings from other studies included in a recent review of factors influencing women's uptake of ANC (13). Fourteen studies in the review confirmed the influence of traditional beliefs on shaping women's ANC seeking behavior, which translated into avoiding biomedical care (13). Additionally, 16 studies that were included in the review established that for many women, pregnancy is still considered as a normal event that does not require medical attention, especially in LMICs (13). 
These traditional beliefs are unlikely to be solely religious in nature, as many Muslim women in other rural areas in Aleppo, such as Afrin district and in rural Latakia, did seek ANC. These beliefs are perhaps more likely to be associated with adopted values, based on shared information in certain communities which did not disappear with time, or changed via positive interaction with the health system, possibly due to the isolation of these communities as well as the lack of interaction with other communities or the medical system, which may have contributed to increasing those women's vulnerability. Consequently, alternative logical explanations of illnesses may have been less available to the women in these communities. This was unlikely the case for Latakia, as its smaller size and its geographical location on the Mediterranean sea may have permitted additional exposure to the outer world, increased their access to education and consequently resulted in a wider exposure to endorsed information.

When women considered seeking ANC or managed to seek care, issues related to accessibility (geographical and financial) and acceptability of different types of ANC services arose. Women's accessibility to and acceptability of ANC services they were exposed to resulted in seeking care with unqualified providers such as midwives or discontinuing their care.

Women often evaluated the risks entailed in accessing ANC services. Accessibility of services was a challenge for many women in Aleppo, especially for vulnerable women with limited mobility and restricted access to financial resources. For instance, services were not always located within close proximity to where women lived especially for poor women in urban Aleppo. Some of these women considered the road trip to seek ANC as risky given the poor road conditions and the lack of regular transportation. Additionally, although it was not brought up during the interviews, women in traditional societies such as in Aleppo, are not allowed to leave the house unaccompanied, which makes seeking care even harder when services are not easily accessible. Therefore, even when women wanted to seek care despite their communities' beliefs that did not perceive ANC as important, they were often faced with traditional norms that did not favor women going out alone. Accessing ANC becomes even more challenging when women are obliged to pay for transportation to go to a public health center or pay for ANC provided at private clinics that are closer to where they live. Travel related risks resulting from inadequate infrastructure, distance to health facilities and lack of transportation were also brought up as barriers to ANC uptake in several studies included in a review that looked at reasons why women do not use ANC in LMICs (14).

Other concerns that women brought up regarding seeking ANC with qualified providers were fear of hearing false bad news and fear of undergoing a cesarean section. Such fears clearly reflect the women's lack of trust in biomedical care. Preferences for normal vaginal childbirth were brought by women in rural Bangladesh in a study that examined women and obstetricians' attitudes towards cesarean delivery (25), however, the study revealed that women trusted their doctors' decisions performing cesarean sections unlike the women in this study who decided to discontinue ANC or seek care with midwives. Those concerns are likely to have been transmitted to those women by other members in their community, which considered seeking ANC as risky and which resulted in inadequate uptake of ANC.

A positive pregnancy experience is of extreme importance to women across different socioeconomic and cultural backgrounds (26). Many women seeking ANC at public health facilities found ANC services

Page $14 / 24$ 
provided at those health facilities to be unacceptable or less satisfactory. Some women brought up issues of lack of trust in public health care providers and being maltreated at public health centers (PHCs), which translated into either going to a private doctor, seeking care with an independent midwife or discontinuing ANC when women could not afford private health care. Poor staff attitude was among the main factors that prevent women from seeking ANC as demonstrated by a review that examined reasons why women seek ANC in LMICs (14). Similarly, a recent study in Saudi Arabia demonstrated that the negative attitude of the staff and poor communication prevented women from attending ANC despite their awareness of its importance (27). The same study also demonstrated the importance of the beliefs of others including family and community members and how they impaired women's access to ANC (27).

To avoid undergoing a cesarean section, to avoid being mistreated by doctors practicing at the public health sector and to avoid paying for private care, many women resorted to seeking care with midwives in Aleppo who charged lower fees than private doctors. Another potential explanation of why many women preferred care with midwives, which was not brought up by women, was because they preferred seeking care with a female health provider, which is particularly important for traditional women in Aleppo. A previous study that included 500 women in Damascus, Syria, confirmed women's preferences for females as birth attendants (28), so we assume that this might have been the case for women in Aleppo. Our results indicated that some women were willing to travel and pay for transportation to seek care with midwives whose clinics were not necessarily close to where they lived, which is also an indication that women are willing to overcome accessibility barriers when they perceive services as being acceptable. Although, acceptability of services was sometimes based on women's own experiences, our interviews indicated that on many occasions, women's choice for certain health providers was largely influenced by stories they heard from others in their communities, which considered ANC provided at PHCs that could have been available and accessible as being unacceptable.

The above-discussed issues relate to women's agency and putting to use the ideas and knowledge present in their families and communities. However, it is important to note that women's agency in the evaluation and decision whether to use services, is imbedded within gendered hierarchical structures of families and communities. In rural and poor urban areas in Aleppo, women appeared to be more vulnerable given their lower educational level and socio-economic status, which consequently may have limited their mobility and reduced their access to financial resources. Those women did not present themselves as having a great deal of control or insight into the management of their pregnancy. The majority of women living in Manbij district justified not seeking care at a health facility or with a private doctor in relation to the prevalent sociocultural norms in their community. The role of social networks and the influence of community were also evident in relation to access to resources such as transport and financial resources. Even when women wished to seek care despite their community beliefs, the socio-cultural norms may have prevented them.

The results of the current study have important implications for consideration of introducing low cost interventions that address the demand side barriers to adequate uptake of ANC. Figure 1 provides an overview of the main themes and sub-themes resulting from this study. Theme 1 translates into perceptions of benefits of ANC, which were related to the availability and acceptability of services. Theme 2 translates into perceptions of risks of seeking ANC, which were related to accessibility to (geographical and financial) 
as well as acceptability of services. Theme 3 translates into perceptions of quality of ANC services, which were related to availability and acceptability of certain types of ANC services. Overall, this study demonstrated that perceptions of benefits, risks and quality of ANC were largely related to the beliefs and experiences of others in the community and were often dependent on misconceptions that resulted in inadequate uptake of ANC.

Although universal health coverage is important to achieve positive health outcomes, its effectiveness becomes limited when services are not used or under-used. Our study demonstrated that vulnerable women, such as women in Aleppo were less likely to demand for ANC services even when they were available and accessible. Future interventions intending to increase adequate uptake of ANC should aim at addressing the needs of vulnerable women and strengthening their capacity and capabilities to enable them to make their own decisions without having to depend on the opinions of others (18). We recommend 3 promising and inter-related approaches to strengthen women's competencies and eventually improve their uptake of ANC: education, empowerment using women's groups and Mobile Health Technologies (mHealth) as potential platforms to deliver education and empowerment interventions.

Increasing women's access to education improves their status in the household and the community, improves their knowledge of ANC benefits and their knowledge about existing services and appropriate types of providers, thus increasing the likelihood of their adequate uptake of ANC. When education is coupled with empowerment, it improves women's accessibility to health services especially when women are able to go out without the need to have a companion and when they have an increased access to financial resources. Additionally, education and empowerment improve women's ability to communicate effectively with health care providers thus enabling them to raise their concerns regarding any negative news they may receive or regarding undergoing a caesarean section hence reducing the likelihood of being mistreated by health providers, and consequently improving their acceptability of ANC services that are offered by qualified health providers.

Empowerment using community mobilization through women's groups has been shown to be an effective strategy in improving maternal and birth outcomes in poor settings $(18,29-32)$. Women's groups are particularly recommended in poor settings to provide support to pregnant women, giving them the opportunity to discuss their needs and the barriers they face when seeking care and encourage them to seek care at health facilities (31-33).

The use of mobile phones was not widespread around the time of the study, especially among rural and poor women. Additionally, social platforms such as WhatsApp, which permits the free exchange of text and audio messages, were also not available. Given the high prevalence of mobile phones use these days, using Mobile Health technologies (mHealth) offers an effective and a low cost platform to promote behavior change and increase vulnerable women's uptake of ANC. A systematic review on the effectiveness of using mHealth in improving usage of ANC demonstrated that there is a strong evidence that delivering text messages reminders and education to the phones of pregnant women can improve their uptake of ANC (34). 
When designing interventions for vulnerable women with limited mobility and reduced access to financial resources, it is important to consider interventions with a delivery mechanism that meets their needs. In the context of Syria, mHealth can be an effective platform to deliver such interventions without the need for women to leave their homes or use transportation, which is particularly important in settings where insecurity remains to be a major concern. Such platforms can be used to send text messages reminders and deliver educational text and audio recorded messages on the importance of seeking ANC, risks of not seeking care and on available PHCs that provide ANC that are close to where women live. Also, mHealth can be an effective platform to deliver empowerment interventions. Such low cost interventions using existing resources are worth being explored in a low resource setting such as in Syria.

One of the main strengths of this study is that, unlike many studies, it interviewed many women twice and at different stages of their pregnancy, thus, it allowed to explore the effects of the pregnancy progress as well as the interaction with the health system on women's health care seeking behavior and their choice of different types of ANC providers. The study also employed participant observation sessions, which aided in triangulation of the results.

The sample included in this study is not be representative of all women in both governorates, but as in any qualitative research, the sample is not usually selected for statistical representativeness, as the main objective of the study is to understand social processes. We could have missed important information by not including more women in rural Latakia. However, quantitative analyses of earlier surveys demonstrated that both rural and urban women in Latakia seek adequate ANC.

Using observation as a data collection tool involves some limitations. Firstly, observation is a subjective event and susceptible to observer bias. The researcher ensured to report the events as they occurred without allowing her own judgment to influence her notes, but she also recorded her own perception and reactions to the events. The second drawback of observation is the "Hawthorne effect," that is, people usually perform better when they know they are being observed. The researcher's presence in health facilities where she conducted observation sessions might have made doctors and staff working at those settings uncomfortable thus influencing their behaviour. The researcher tried to avoid that by visiting those settings several times and at different circumstances, so doctors and staff were used to her presence. When possible, she visited the same settings at different days and different times to assess the processes of care in different circumstances. We suspect that the researcher's presence did not change the doctors' daily behaviour during the visits, as she did not specify what she was looking for during these observation sessions.

Interviewing women at home made them feel more at ease, since they were at a familiar setting. However, since many of them lived in households with many family members, interviews were often interrupted, and other family members like mothers and mothers in -law who participated occasionally. Moreover, the presence of other family members might have made women feel less comfortable discussing their health seeking behaviour and biased their answers. Thus, to avoid this kind of bias, we interviewed women in Aleppo for a second time and for a longer period, which helped to build rapport, encouraging the women to 
feel more at ease and comfortable sharing information about their ANC practices, and providing more opportunities to interview them alone.

Courtesy bias, where women tried to give answers in favour of their doctors might have occurred with women in Latakia, as most participants preferred to be interviewed at health facilitates. Consequently, being interviewed at health facilities where those women received ANC might have biased their answers towards favouring the services they have received at these particular clinics or health centres and might have discouraged them from discussing the issues that they were not entirely satisfied with.

\section{Conclusions}

We believe that our proposed interventions are likely to be effective in addressing the demand-side barriers to adequate uptake of ANC that existed pre-conflict and which were likely to have persisted post-conflict. Such interventions could be also explored to increase women's uptake of other maternal health care services including family planning and use of modern contraception methods. Furthermore, given the physical destruction caused by the conflict, which led to a decrease in the number of health facilities and which instigated the internal displacement of a large number of people (464,800 estimated in January 2020) (35), future research is needed to explore the additional demand side barriers that internally displaced women are currently experiencing when seeking ANC in their new host communities and as a result of using new and probably strained health facilities. Crafting appropriate interventions to increase women's uptake of ANC is likely to be more effective when it is contextual and when it addresses the barriers that women are presently facing.

\section{Abbreviations}

ANC

Antenatal Care

LMICs

Lower and Middle-Income Countries

MICS

Multiple Indicator Cluster Survey

PAPFAM

Pan Arab Project for Family Health

PHCs

Public Health Centers

WHO

World Health Organization

\section{Declarations}

\section{Ethics approval and consent to participate}


Ethics approval for this study was obtained from the IRB at the London School of Hygiene and Tropical Medicine and by University of Damascus, Syria.

Verbal consent was obtained from women with the presence of a research assistant. The study was explained to women by the researcher while emphasizing that their participation is voluntary and that they may withdraw at any time without giving a reason. Study participants were reassured that their participation would remain anonymous and that their names would not be mentioned in any research output or published materials.

\section{Consent for publication}

Consent was obtained from all the participants to publish information obtained from them but without the personal identifiers. These were also witnessed accordingly.

\section{Availability of data and materials}

The datasets used and/or analyzed during the current study are available from the corresponding author on reasonable request.

\section{Competing interests}

The authors declare that they have no competing interests.

\section{Funding}

This study was made possible by funding from the Wellcome Trust.

\section{Authors' contributions}

RM conceptualized the study and collected the data. RM analysed the data with FH's input. RM wrote the paper. FH commented on several drafts of the paper. HB commented on the final draft of the paper.

\section{Acknowledgements}

We would like to thank the Syrian Ministry of Health and the Health directorates in Aleppo and Latakia. We would like to thank Dr Oona Campbell (London School of Hygiene and Tropical Medicine) for her great contribution in conceptualizing the study. We also thank all women who participated in this study.

\section{References}


1. Alkema L, Chou D, Hogan D, Zhang S, Moller AB, Gemmill A, Fat DM, Boerma T, Temmerman M, Mathers C, Say L. Global, regional, and national levels and trends in maternal mortality between 1990 and 2015, with scenario-based projections to 2030: a systematic analysis by the UN Maternal Mortality Estimation Inter-Agency Group. The Lancet. 2016 Jan 30;387(10017):462 - 74.

2. Cousens S, Blencowe H, Stanton C, Chou D, Ahmed S, Steinhardt L, Creanga AA, Tunçalp Ö, Balsara ZP, Gupta S, Say L. National, regional, and worldwide estimates of stillbirth rates in 2009 with trends since 1995: a systematic analysis. The Lancet. 2011 Apr;16(9774):1319-30. 377(.

3. World Health Organization. WHO recommended interventions for improving maternal and newborn health: integrated management of pregnancy and childbirth. World Health Organization; 2007.

4. Tunçalp Ó!, Pena-Rosas JP, Lawrie T, Bucagu M, Oladapo OT, Portela A, Gülmezoglu AM. WHO recommendations on antenatal care for a positive pregnancy experience-going beyond survival. Bjog. 2017 May 1;124(6):860-2.

5. Kolsteren PW, De Souza S. Micronutrients and pregnancy outcome. Safe motherhood strategies: a review of the evidence. 2001.

6. WHO Antenatal Care Trial Research Group Carroli G, Villar J, Piaggio G, Khan-Neelofur D, Gülmezoglu M, Mugford M, Lumbiganon P, Farnot U, Bersgj $\varnothing$ P. WHO Antenatal Care Trial Research Group. WHO systematic review of randomised controlled trials of routine antenatal care. The Lancet. 2001 May 19;357(9268):1565-70.

7. AbouZahr C, Wardlaw T. Antenatal care in developing countries: promises, achievements and missed opportunities-an analysis of trends, levels and differentials, 1990-2001. World Health Organization; 2003.

8. World Health Organization. WHO recommendations on antenatal care for a positive pregnancy experience: summary: highlights and key messages from the World Health Organization's 2016 global recommendations for routine antenatal care. World Health Organization; 2018.

9. Ensor T, Cooper S. Overcoming barriers to health service access: influencing the demand side. Health policy and planning. 2004 Mar 1;19(2):69-79.

10. O'Donnell 0 . Access to health care in developing countries: breaking down demand side barriers. Cadernos de saude publica. 2007 Dec;23(12):2820-34.

11. Peters DH, Garg A, Bloom G, Walker DG, Brieger WR, Hafizur Rahman M. Poverty and access to health care in developing countries. Annals of the New York Academy of Sciences. 2008 Jun;1136(1):161 71.

12. Simkhada B, Teijlingen ER, Porter M, Simkhada P. Factors affecting the utilization of antenatal care in developing countries: systematic review of the literature. Journal of advanced nursing. 2008 Feb;61(3):244-60.

13. Downe S, Finlayson K, Tunçalp Ö, Gülmezoglu AM. Provision and uptake of routine antenatal services: a qualitative evidence synthesis. Cochrane Database of Systematic Reviews. 2019(6).

14. Finlayson K, Downe S. Why do women not use antenatal services in low-and middle-income countries? A meta-synthesis of qualitative studies. PLoS Med. 2013 Jan;22(1):e1001373. 10(. 
15. Syrian Central Bureau of Statistics. League of Arab States. Family Health Survey in Syrian Arab Republic - 2009, 2011.

16. Mourtada R. Mixed Method Analysis of Factors Affecting Antenatal Care Content: A Syrian Case Study: London School of Hygiene and Tropical Medicine, 2014. PhD thesis.

17. Abbara A, Blanchet K, Sahloul Z, Fouad F, Coutts A, Wasim M. The effect of the conflict on Syria's health system and human resources for health. World health \& population. 2015 Sep 30;16(1):87-95.

18. Elmusharaf K, Byrne E, O’Donovan D. Strategies to increase demand for maternal health services in resource-limited settings: challenges to be addressed. BMC Public Health. 2015 Dec;15(1):1-0.

19. Pope C, Mays N. Qualitative methods in health research. Qualitative research in health care. 2006 Jan 1;3:1-1.

20. Mays N, Pope C. Qualitative research: observational methods in health care settings. Bmj. 1995 Jul 15;311(6998):182-4.

21. Mulhall A. In the field: notes on observation in qualitative research. Journal of advanced nursing. 2003 Feb;41(3):306-13.

22. Ritchie J, Spencer L. Qualitative data analysis for applied policy research. The qualitative researcher's companion. 2002 Mar 19;573(2002):305-29.

23. Pope C, Ziebland S, Mays N. Analysing qualitative data. Bmj. 2000 Jan 8;320(7227):114-6.

24. Kridli SA. Health beliefs and practices among Arab women. MCN: The American Journal of Maternal/Child Nursing. 2002 May 1;27(3):178 - 82.

25. Begum T, Ellis C, Sarker M, Rostoker JF, Rahman A, Anwar I, Reichenbach L. A qualitative study to explore the attitudes of women and obstetricians towards caesarean delivery in rural Bangladesh. BMC Pregnancy Childbirth. 2018 Dec;18(1):368.

26. Downe S, Finlayson K, Tunçalp Ó', Metin Gülmezoglu A. What matters to women: a systematic scoping review to identify the processes and outcomes of antenatal care provision that are important to healthy pregnant women. BJOG: An International Journal of Obstetrics Gynaecology. 2016 Mar;123(4):529-39.

27. Alanazy W, Rance J, Brown A. Exploring maternal and health professional beliefs about the factors that affect whether women in Saudi Arabia attend antenatal care clinic appointments. Midwifery. 2019 Sep 1;76:36-44.

28. Bashour H, Abdulsalam A. Syrian women's preferences for birth attendant and birth place. Birth. 2005 Mar;32(1):20-6.

29. Manandhar DS, Osrin D, Shrestha BP, Mesko N, Morrison J, Tumbahangphe KM, Tamang S, Thapa S, Shrestha D, Thapa B, Shrestha JR. Effect of a participatory intervention with women's groups on birth outcomes in Nepal: cluster-randomised controlled trial. The Lancet. 2004 Sep 11;364(9438):970-9.

30. Prost A, Colbourn T, Seward N, Azad K, Coomarasamy A, Copas A, Houweling TA, Fottrell E, Kuddus A, Lewycka $S$, MacArthur C. Women's groups practising participatory learning and action to improve maternal and newborn health in low-resource settings: a systematic review and meta-analysis. The Lancet. 2013 May 18;381(9879):1736-46.

31. World Health Organization 
WHO recommendation on facilitated participatory learning and action cycles with women`s groups during pregnancy

World Health Organization. WHO recommendation on facilitated participatory learning and action cycles with women`s groups during pregnancy. 2018. https://extranet.who.int/rhl/topics/improvinghealth-system-performance/implementation-strategies/who-recommendation-facilitated-participatorylearning-and-action-cycles-womens-groups-during.

32. Ishaku SM. Engaging community women's groups for improved uptake of antenatal care services in Cross River State, Nigeria: An analysis of post-intervention findings.

33. Kearns AD, Caglia JM, ten Hoope-Bender P, Langer A. Antenatal and postnatal care: a review of innovative models for improving availability, accessibility, acceptability and quality of services in lowresource settings. BJOG: An International Journal of Obstetrics Gynaecology. 2016 Mar;123(4):540-8.

34. Watterson JL, Walsh J, Madeka I. Using mHealth to improve usage of antenatal care, postnatal care, and immunization: a systematic review of the literature. BioMed research international. $2015 \mathrm{Jan}$ $1 ; 2015$.

35. OCHA. Syrian Arab Republic

OCHA. Syrian Arab Republic. Movements IDP. January 2020.

https://reliefweb.int/sites/reliefweb.int/files/resources/idpmovements_202001jan_final_en.pdfAcessed on May 22nd, 2020.

\section{Tables}

Table 1: The general characteristics of Aleppo and Latakia governorates (2010)

\begin{tabular}{|l|l|l|}
\hline & Aleppo & Latakia \\
\hline Location & Northern Syria & Western Syria \\
\hline Land area & $1,850,000$ hectares & 230,000 hectares \\
\hline Population & $5,927,000$ & $1,229,000$ \\
\hline $\begin{array}{l}\text { Number of } \\
\text { districts }\end{array}$ & 8 & 4 \\
\hline Number of villages & 1,453 & 432 \\
\hline Religion & $\begin{array}{l}90 \% \text { are Muslims; the majority are } \\
\text { Sunnis, mostly Arabs, followed by } \\
\text { Kurds. The rest (10\%) are Christians } \\
\text { and Armenians }\end{array}$ & $\begin{array}{l}\text { Mostly Alawites with some Sunni } \\
\text { Muslims and Greek Orthodox } \\
\text { Christians }\end{array}$ \\
\hline
\end{tabular}


Table 2: An overview of the interviewed women in Aleppo and Latakia governorates

\begin{tabular}{|l|l|l|l|}
\hline & Women in Aleppo & Women in Latakia & Total \\
\hline Private clinics/hospitals & 4 & 7 & 11 \\
\hline Public health centers/hospitals & 4 & 5 & 9 \\
\hline Midwives clinics & 5 & NA & 5 \\
\hline No ANC & 5 & NA & 5 \\
\hline Total & 18 & 12 & 30 \\
\hline
\end{tabular}

\section{Figures}

\begin{tabular}{|c|c|c|c|}
\hline Themes & $\begin{array}{l}\text { Theme 1: Women's assessment of their } \\
\text { own health status in pregnancy and } \\
\text { reasoning about the causes of ill health }\end{array}$ & $\begin{array}{l}\text { Theme 2: Women's evaluation of the risks of } \\
\text { seeking ANC services }\end{array}$ & $\begin{array}{l}\text { Theme 3: Women's appraisal of the value of } \\
\text { different types of service providers }\end{array}$ \\
\hline Sub-Themes & $\begin{array}{l}\text { 1-Not experiencing complications } \\
\text { 2-Not being primiparas } \\
\text { 3-Lack of perceived benefits of ANC and } \\
\text { reasoning about the causes of ill health in } \\
\text { pregnancy }\end{array}$ & $\begin{array}{l}\text { 1- Concerns over the road trip } \\
\text { 2- Fear of hearing false bad news } \\
\text { 3- Fear of undergoing a caesarean section }\end{array}$ & $\begin{array}{l}\text { 1- Lack of knowledge about services provided } \\
\text { at PHCs } \\
\text { 2- Lack of trust in services provided at the PHC } \\
\text { 3- Poor experiences of patient-provider } \\
\text { interactions at public health }\end{array}$ \\
\hline Summary & Perceptions of benefits of ANC & Perceptions of risks of ANC & Perceptions of quality of ANC services \\
\hline $\begin{array}{l}\text { The health } \\
\text { access model }\end{array}$ & Availability \& Acceptability & $\begin{array}{c}\text { Accessibility (geographical \& financial) \& } \\
\text { Acceptability }\end{array}$ & Availability and Acceptability \\
\hline $\begin{array}{l}\text { ANC seeking } \\
\text { patterns }\end{array}$ & Not seeking ANC at all & $\begin{array}{l}\text { Not seeking care at all, seeking care with } \\
\text { unqualified providers or discontinuing care }\end{array}$ & $\begin{array}{l}\text { Changing health providers, seeking care with } \\
\text { unqualified providers or discontinuing care }\end{array}$ \\
\hline $\begin{array}{l}\text { Potential } \\
\text { interventions } \\
\text { to address } \\
\text { demand side } \\
\text { barriers to } \\
\text { improve } \\
\text { uptake of } \\
\text { ANC }\end{array}$ & $\begin{array}{l}\text { Education: } \\
\text { * Improves knowledge about available } \\
\text { ANC services and type of services } \\
\text { provided by different types of providers } \\
\text { (private, public). } \\
* \text { Improves knowledge of ANC benefits } \\
\text { and the risks of not seeking care } \\
\text { (improving their acceptability of } \\
\text { services). } \\
\text { Empowerment: } \\
* \text { Encourages women to seek ANC } \\
\text { despite their community's preferences } \\
\text { and expectations. } \\
\text { mHealth tools: A platform to deliver } \\
\text { messages to promote behavior change and } \\
\text { increase uptake of ANC }\end{array}$ & $\begin{array}{l}\text { Education: } \\
\% \text { Improves knowledge about different types of } \\
\text { ANC services and providers reducing the } \\
\text { probability of seeking ANC with unqualified } \\
\text { providers. } \\
\text { Empowerment: } \\
* \text { Enables women to go out without a } \\
\text { companion (improving geographical } \\
\text { accessibility). } \\
* \text { Increases their access to finances (improving } \\
\text { financial accessibility). } \\
* \text { Enables women to communicate more } \\
\text { effectively with health providers (improving } \\
\text { their acceptability of services and reducing } \\
\text { the probability of seeking ANC with } \\
\text { unqualified providers). } \\
\text { mHealth tools: A platform to deliver messages } \\
\text { to promote behavior change and increase uptake } \\
\text { of ANC }\end{array}$ & $\begin{array}{l}\text { Education: } \\
\text { * Improves knowledge about the available } \\
\text { PHCs that are closest to where women live } \\
\text { and services provided at those PHCs. } \\
\text { Empowerment: } \\
* \text { Enables women to communicate more } \\
\text { effectively with health providers (improving } \\
\text { their acceptability of services and reducing } \\
\text { the probability of discontinuing care or } \\
\text { seeking ANC with unqualified providers). } \\
\text { mHealth tools: A platform to deliver messages } \\
\text { to promote behavior change and increase } \\
\text { uptake of ANC }\end{array}$ \\
\hline
\end{tabular}

\section{Figure 1}

A summary of potential interventions addressing the demand-side barriers to increase women's uptake of ANC services

Supplementary Files 
This is a list of supplementary files associated with this preprint. Click to download.

- Additionalfile1.pdf 